\title{
A LEI ANTITERRORISMO BRASILEIRA E A (I)LEGITIMIDADE DE SEUS MECANISMOS CARACTERÍSTICOS DE UM “DIREITO PENAL DO INIMIGO”
}

\author{
Jordan Espíndola dos Santos* \\ Antonio Sergio Cordeiro Piedade**
}

\section{RESUMO}

O artigo visa analisar a Lei antiterrorismo brasileira, partindo da consideração de que alguns mecanismos nela positivados guardam semelhança com ditames do funcionalismo sistêmico de Günter Jakobs, tais como a antecipação da tutela penal com tipificação de atos preparatórios e de tipos de perigo, e o uso de meios investigativos aprimorados e relativamente mais invasivos. Busca-se por meio de pesquisa exploratória, com abordagem quantitativa, técnica bibliográfica e documental, e com a hermenêutica como procedimento metodológico, compreender a legitimidade e adequação de alguns desses dispositivos característicos do chamado "Direito Penal do Inimigo” para a efetiva tutela dos bens jurídicos envolvidos.

Palavras-chave: lei antiterrorismo, funcionalismo sistêmico, Günter Jakobs.

\section{THE BRAZILIAN ANTITERRORISM LAW AND THE (IL)LEGITIMACY OF ITS MECHANISMS CHARACTERISTIC OF A "CRIMINAL LAW OF THE ENEMY"}

\begin{abstract}
The article aims at analyzing the Brazilian Antiterrorism Law, starting from the consideration that some mechanisms in it are in keeping with the dictates of Günter Jakobs' systemic functionalism, such as the anticipation of criminal tutelage with the classification of preparatory acts and types of danger, and the use of improved and relatively more invasive investigative means. It is sought through exploratory research, with a quantitative approach, bibliographical and documentary technique, and with hermeneutics as a methodological procedure, to understand the legitimacy and adequacy of some of these characteristic devices of the so-called "Criminal Law of the Enemy" for the effective protection of property Involved.
\end{abstract}

Keywords: Anti-terrorism law, systemic functionalism, Günter Jakobs.

\footnotetext{
* Mestrando em Direito pela Universidade Federal de Mato Grosso. Oficial da Polícia Militar de Mato Grosso. jordan@pm.mt.gov.br.

** Mestre e Doutor em Direito Penal pela PUC-SP. Professor da Graduação e do Mestrado em Direito da Faculdade de Direito da Universidade Federal de Mato Grosso. Promotor de Justiça em Mato Grosso.
} 


\section{INTRODUÇÃO}

No presente trabalho trataremos da Lei antiterrorismo brasileira, Lei $n^{\circ} 13.260$, aprovada em fevereiro de 2016, especialmente de alguns dos seus dispositivos enrijecedores do tratamento penal e processual penal às condutas consideradas terroristas.

A análise se dará sob o ponto de vista da necessidade, constitucionalidade e legitimidade de mecanismos penais e processuais que guardam semelhança ou mesmo características do modelo funcionalista sistêmico de Günter Jakobs, denominado de “direito penal do inimigo".

Com a promulgação da lei antiterrorismo e sua recente entrada em vigor, algumas intrigantes indagações vem à tona. Para além da mera análise acerca de sua constitucionalidade, objetiva-se questionar se são legítimos os mecanismos característicos do funcionalismo radical ou sistêmico de Jakobs, positivados na lei por meio de dispositivos que ensejam tipificação relativamente aberta, antecipação da tutela penal com a punição de atos preparatórios e a previsão de tipos de perigo (concreto ou abstrato), e ainda a relativização de algumas garantias penais e processuais com a aplicação das disposições das leis de organizações criminosas e de crimes hediondos. A pergunta que mais interessa não é necessariamente se a lei antiterrorismo brasileira reflete um direito penal do inimigo, mas sim se a lei, ou se seus mecanismos específicos característicos desse modelo idealizado por Jakobs, são legítimos e adequados aos fins que se destinam.

É cada vez maior a relevância da pesquisa sobre os modelos de atuação estatal e a política criminal diante das chamadas novas formas de criminalidade (dentre as quais se insere o terrorismo), cujo alcance pela dogmática penal clássica tem demonstrado sérias lacunas de proteção, o que pode levar a graves prejuízos. Objetiva-se então, refletir acerca do papel do direito penal diante do terrorismo, e se a dogmática deve evoluir a ponto de tornar o direito penal um instrumento hábil à tutela dos bens jurídicos colocados em risco pelos atos terroristas, além do cotejo entre o patamar atual da dogmática e esse tipo de criminalidade.

Para atingirmos a tais objetivos, trabalharemos num primeiro momento as relações entre o terrorismo e o Direito Penal, sobretudo o modelo de Jakobs e seu emprego em legislações de "combate" ao crime de terrorismo e outras formas contemporâneas de criminalidade, para em seguida propor o debate em relação à necessidade, adequação e legitimidade dos mecanismos da nova lei antiterrorismo brasileira. 
A pesquisa realizada é de cunho meramente exploratório, uma vez que visa proporcionar uma maior familiaridade com esse instigante e atualíssimo tema. A abordagem das compreensões jurídicas é qualitativa, e as técnicas de pesquisa adotadas são predominantemente a bibliográfica (em livros e outras produções científicas) e a documental (legislação e julgados). Quanto ao procedimento metodológico, como não poderia ser diferente ante à necessidade de compreensão de institutos jurídicos, é a hermenêutica jurídica, que se presta à interpretação ampla e sistemática das normas jurídicas, e cuja função, segundo o professor Tércio Sampaio Ferraz Junior (2007, p. 256), é a “determinação do sentido das normas, o correto entendimento do significado dos seus textos e intenções, tendo em vista a decidibilidade de conflitos”.

\section{O TERRORISMO PERANTE O FUNCIONALISMO SISTÊMICO DE GUNTER} JAKOBS: O DIREITO PENAL DO INIMIGO E SUAS PRINCIPAIS CARACTERÍSTICAS E CRÍTICAS

O terrorismo é comumente enquadrado como uma das novas ameaças à coletividade, uma das maiores juntamente com o risco de guerra nuclear e a temeridade de desastres naturais. Como nova ameaça, tem exigido da humanidade também novos e mais aprimorados mecanismos de prevenção e repressão, embora a história mostre que não é exatamente o terrorismo que é algo novo, mas sim as proporções dos ataques terroristas é que têm atingido um patamar de nova ameaça.

Numa franca tentativa de conceituação, Marcos Degaut (2014) expõe que simplificadamente, o terrorismo consiste no emprego da intimidação coercitiva por movimentos revolucionários, regimes ou indivíduos, com motivação política. Para ele, trata-se de um “método em que um grupo político organizado procura atingir suas finalidades declaradas, principalmente por meio do uso motivado, premeditado e sistemático da violência contra populações não-combatente” (DEGAUT, 2014).

Conforme se depreende do singelo conceito, o terror possui um grande peso simbólico, dada tamanha magnitude ou atrocidade dos ataques, o que faz com que o medo ganhe espaço e, com ele, o clamor por soluções de cunho radical (ALMEIDA, et. al., 2017).

A compreensão da questão do medo e suas consequências ao âmbito jurídico é interessante para a necessária reflexão acerca da implementação de legislações antiterrorismo, 
e para tanto é oportuna a doutrina de Zygmunt Bauman, na linha tratada em algumas de suas obras.

O mestre polonês trabalha em algumas de suas obras o alastramento da chamada mixofobia, o medo de se misturar em relação aos perigos que permeiam (aqueles que chama de) os “outros”, aqui enxergados como os estrangeiros, os que cultuam religiões distintas, os menos abastados, etc. Diante da emergência terrorista, os cidadãos requerem respostas imediatas. Se os perigos que o homem mais teme são imediatos, compreensivelmente deseja-se que os remédios também o sejam. A busca por doses rápidas, que oferecem alívio imediato é constante. Embora as raízes do perigo sejam dispersas ou nem sempre compreendidas, é natural a busca por defesas simples e prontas a serem empregadas imediatamente (BAUMAN, 2008). Tal constatação de Bauman deve ser levada em consideração na busca de um equilíbrio na implementação dos mecanismos de trato com o terrorismo.

O grande esforço na busca pela segurança deve ser sempre dosado com o risco de invasão excessiva do poderio do Estado nas mais fundamentais liberdades individuais, para que o sentimento de insegurança não transforme as ações de cunho policialesco em rotina, o que faz com que o medo cresça sempre em progressão geométrica.

Conforme reflete Bauman, desta vez na obra Danos Colaterais:

\begin{abstract}
O paradoxo da segurança é que, quanto mais ela funciona, menos deveria ser necessária. Mas, em vez disso, a necessidade de segurança pode tornar-se viciante. Proteção e segurança nunca são suficientes. Quando você começa a traçar e fortificar fronteiras, não há como parar. O principal beneficiário é nosso medo; ele floresce e prolifera alimentando-se de nossos esforços de traçar e armar fronteiras” (Bauman, 2013, p. 90).
\end{abstract}

Ainda sobre as reações do ser humano ao medo, e utilizando a ideia de Bobbio (1986, p. 73), os cidadãos “acatam a ideia de que para males extremos são necessários remédios extremos”. Porém, deve-se observar que este panorama fundado num espírito de dura vingança contra tais males pode levar a um ciclo vicioso. A ameaça do terrorismo pode levar a mais terror, majorando o sentimento de medo e insegurança e levando massas cada vez maiores de pessoas aterrorizadas (BAUMAN, 2008).

Embora faça esse alerta quanto às perigosas reações ao terrorismo impulsionadas pelo sentimento de medo, o próprio Bauman contrapõe que "mesmo na eventualidade de que as fronteiras sejam fechadas aos viajantes indesejáveis de carne e osso, a probabilidade de outro atentado terrorista não pode ser reduzida a zero” (Bauman, 2008, p. 161). A colocação acima 
parecer ser óbvia, uma vez que a ameaça terrorista prescinde de análises de probabilidade mínima, uma vez que está inserta na realidade mundial. O esforço feito para explicar os riscos das respostas temerárias ao terrorismo, no entanto, não parece ser o mesmo que o esforço na tentativa de discutir os possíveis legítimos e efetivos remédios (para falar como o mestre) para o tratamento a esse mal.

Vejamos então o que vem a ser o modelo de Jakobs, cuja referência ao combate ao terrorismo é expressa.

\subsection{O modelo funcionalista sistêmico (o “Direito Penal do inimigo”)}

De acordo com a evolução mais recente da dogmática penal, após estabelecido o finalismo e suas vertentes vem à tona o funcionalismo, que busca uma relação maior da dogmática implementada ao plano prático. Paula Neves Brigagão (2010) bem apresenta o que a doutrina tem reconhecido como as três vertentes do funcionalismo penal:

\footnotetext{
preocupa-se o funcionalismo penal com o verdadeiro sentido e alcance do Direito Penal no cenário jurídico-mundial. Sua função se reveste da própria ontologia conceitual desse ramo do Direito. O Funcionalismo Moderado (também conhecido como Funcionalismo Teleológico) é criação do gênio alemão Claus Roxin. O Funcionalismo Radical (também conhecido como Funcionalismo Sistêmico ou Normativista) é filho único do sociólogo Günter Jakobs. O funcionalismo Reducionista, também conhecido como Limitado, é fruto dos estudos do penalista argentino Eugênio Zaffaroni.
}

Dentre as três versões do funcionalismo a que mais nos interessa é a radical ou sistêmica, que ganhou notoriedade com sua disseminação por Gunter Jakobs. Discípulo de Welzel, Jakobs é considerado um dos mais polêmicos e respeitados juristas da atualidade, e idealizou a teoria do funcionalismo sistêmico com base na Teoria dos Sistemas de Niklas Luhmann. Tal teoria sustenta que o Direito Penal tem como principal função a de reafirmação da vigência da norma. A proteção a bens jurídicos seria consequência ou resultado de sua aplicação (MORAES, 2011). Essa seria, a rigor, sua descrição do Direito Penal da normalidade, ou o que ele denominou de Direito Penal do Cidadão, em contrapartida a um Direito Penal do Inimigo, cujas características veremos adiante.

Segundo o próprio Günther Jakobs, o Direito Penal do Inimigo:

São regras jurídico-penais que, como suas correlatas, as regras do Direito Penal do Cidadão, somente são concebíveis enquanto tipos ideais. O Direito Penal do Inimigo é, essencialmente, violência silenciosa; o Direito Penal do Cidadão é, sobretudo, 
comunicação sobre a vigência da norma. Para exemplificar, o criminoso que se encontra sob custódia de segurança é fortemente despersonalizado pela subtração de sua liberdade, mas conserva seu direito à vida e à liberdade, à propriedade e outros direitos mais; e o cidadão condenado à pena privativa de liberdade por um fato único deve tolerar essa privação como “reparação do dano" por sua agressão à norma. Mas a pena privativa de liberdade também é, ao mesmo tempo, um asseguramento (Jakobs, 2008, p. xxvi).

Pode ser constatada uma evolução da compreensão e posicionamento de Jakobs acerca de suas construções sobre um direito penal do inimigo. A primeira, ainda em meados da década de 80, era a de (simplesmente) descrever a medida de dois direitos penais, um voltado ao cidadão, outro ao inimigo, numa referência crítica à tendência que se instalava na Alemanha.

Já em suas obras e contribuições mais recentes, Jakobs teria, segundo análise de Alexandre Rocha Almeida de Moraes (2011, p. 182), “abandonado claramente sua postura crítica e meramente descritiva, passando a empunhar uma tese afirmativa, legitimadora e justificadora da linha de pensamento”. Ou seja, passou a se mostrar um defensor deste direito penal de terceira velocidade.

A tese tem suporte filosófico especialmente nas concepções contratualistas e de outros filósofos de diferentes vertentes, e o principal aspecto fundamentador (e também o maior alvo de críticas) é o reconhecimento de duas categorias: pessoas x inimigos.

O professor português Manuel Monteiro Guedes Valente faz consistente análise dessa base de compreensões filosóficas contratualistas com a teoria do direito penal do inimigo pautada na dicotomia pessoa (cidadão) versus inimigo. Partindo da teoria do contrato social de Rosseau poder-se-ia aferir alguns de seus apontamentos, ao reconhecer a existência de agentes de crime (delinquentes) que são inimigos, pois cometem delitos graves e colocam em risco o contrato social como pacto de natureza política, e que, por isso, não teriam condição de pessoal moral ou de cidadão. O rompimento com o contrato social por parte destes indivíduos seria renunciar às qualidades de ser como pessoa, e consequente assunção da condição de inimigo. Com Thomas Hobbes se adquire a concepção do que deve ser o inimigo para o Direito Penal. Ele concebe um Direito Penal do inimigo como uma moderna dogmática penal. Seria inimigos aqueles seres humanos que se encontram no estado de natureza, produtores de constante perigo e ameaça à própria existência humana, e que projetam uma falta de segurança coletiva. Tal concepção fez com que Hobbes defendesse um Direito Penal para os maus cidadãos e outro Direito Penal para os inimigos. Já o pensador Immanuel Kant contribui para a concepção de inimigo como sendo este uma ameaça à ordem jurídica instituída, ou uma ameaça permanente 
à segurança jurídica, física e cognitiva da coletividade. Ainda, com base nos pensadores mais recentes, Franz von Liszt não teria impulsionado uma visão belicista do Direito Penal, no entanto ao defender a existência de três categorias de delinquentes, os reincidentes, os habituais e os por tendência, que deveriam ser sujeitados à prisão perpétua ou de duração indeterminada e perda duradoura de determinados direitos civis e políticos, pode-se concluir que von Liszt considera, embora defenda uma política criminal baseada em uma política social, aqueles seres humanos como um exército de inimigos fundamentais da ordem social (VALENTE, 2016).

\subsection{Principais Características}

Interessante quadro faz Alexandre Rocha Almeida de Moraes listando as características do “Direito Penal do Inimigo” de acordo com a visão de vários autores. Pode-se afirmar, com confiança, que três características permeiam esse modelo de política criminal, comum a todos os autores:

a) ampla antecipação da punibilidade (Jakobs), um ordenamento jurídico-penal prospectivo (Meliá), com tipificação de atos preparatórios, criação de tipos de mera conduta e de perigo abstrato (Gracia Martín);

b) penas desproporcionalmente altas; ou desproporcionalidade das penas;

c) mudança de legislação de proteção para legislação de luta ou combate (MORAES, 2011).

Uma quarta característica pode ser elencada: a da relativização ou supressão de determinadas garantias penais e processuais. Mas sobre esta última, desde já cabe uma explicação. Por garantia podemos entender, nesse contexto, qualquer previsão legal que enseje direitos ao cidadão acusado no processo penal, e tal garantia é assim considerada em determinado momento legislativo ou jurídico, já que novas garantias podem ser reconhecidas a todo momento, e outras disposições até então consideradas como garantias podem ser extintas pela compreensão de lei ou entendimento jurídico novo. Para exemplificar: qualquer lei nova que por ventura venha a inovar a disciplina do Código Penal para ampliar por exemplo o tempo de cumprimento de pena para a prescrição ou para a progressão de regime pode ser considerada uma lei que relativizou ou suprimiu uma garantia (ou um direito) que assistia os acusados até então. Essa ressalva é importante para esclarecer que não se está a falar em supressão autoritária ou abusiva de qualquer garantia, como se estivéssemos nos referindo a uma negação ao direito. 
Compreendidas as principais características do modelo, retoma-se a indagação: seria ilegítimo o direito penal do inimigo diante do atual cenário da modernidade e do avanço colossal avanço das novas formas de criminalidade, antes não concebidas pela dogmática clássica, tais como a delinquência patrimonial profissional e organizada, das organizações criminosas com atuação massiva no âmbito da corrupção de agentes públicos de quaisquer dos poderes, ou, principalmente, dos fenômenos terroristas que ameaçam solapar os mais basilares fundamentos dos Estados Democráticos de Direito? Em reflexão acerca de interrogação como essa, Alexandre Rocha Almeida de Moraes (2011, p. 244) aponta:

\footnotetext{
Uma resposta meramente negativa, pautada simplesmente pelos fundamentos clássicos iluministas esconderia a realidade: na prática as legislações de todo o mundo já estão sendo permeadas por modelos, institutos e características de um Direito Penal e Processual de terceira velocidade.

Assim, como acentua Jakobs, é inegável que um 'Direito Penal do Inimigo' claramente delimitado é menos perigoso, na perspectiva do Estado de Direito, que entrelaçar todo o Direito Penal com fragmentos de regulações próprias de um Direito Penal de terceira velocidade.
}

Antes de avançarmos na apreciação dessa possibilidade, é imperiosa a análise das mais contundentes críticas à concepção de Jakobs.

\subsection{Críticas ao modelo}

Importante referenciar e sopesar, desde já, a crítica a uma chamada “cultura da emergência” que pode levar a reações jurídicas ou legislativas inadequadas. O tema é trabalhado na obra intitulada "Emergência e defesa dos Direitos Fundamentais” de Sérgio Moccia (1999), e traz importante alerta acerca da séria problemática que um direito penal emergencial, simbólico, ou mesmo belicista pode ocasionar. De acordo com Luigi Ferrajoli, (2012, p. 650) com a adoção de uma postura emergencial ocorreria uma primazia da razão de estado sobre a razão jurídica como critério informador do direito e processo penal "em que a intervenção punitiva se funda em um critério político que se sobrepõe ao jurídico, não mais subordinandose às garantias da lei. A excepcionalidade, por sua vez, é uma tentativa de abrigar na própria ordem jurídica a exceção”. Ou seja, à época, na década de 1980, o posicionamento de Ferrajoli acerca da evolução penal em resposta ao terrorismo, era de total aversão, e foi inclusive o que motivou a difusão da consagrada teoria do garantismo penal, em meio ao movimento 
denominado magistratura democrática, que se realizou em reação à legislação e postura jurídica antiterrorista na Itália.

Ferrajoli acrescenta (2012, p. 667):

O que quer que se pense do terrorismo e em geral dos fenômenos criminais de gravidade excepcional, apenas as duas respostas acima mencionadas são compatíveis com a lógica do Estado de direito, a qual exclui que se possa configurar a razão de Estado como razão jurídica. A razão jurídica do Estado de direito, de fato, não conhece amigos ou inimigos, mas apenas culpados e inocentes. Não admite exceções às regras senão como fato extra ou antijurídico, dado que as regras - se são levadas a sério, como regras, e não como simples técnicas - não podem ser deixadas de lado quando for cômodo. E na jurisdição o fim não justifica os meios, dado que os meios, ou seja, as regras e as formas, são as garantias de verdade e liberdade, e como tais tem valor para os momentos difíceis, assim como para os momentos fáceis; enquanto o fim não é mais o sucesso sobre o inimigo, mas a verdade processual, a qual foi alcançada apenas pelos seus meios e prejudicada por seu abandono.

Fazendo coro a essa crítica à expansão do direito penal, D àvila (2013, p. 68) observa que esta luta contra o terrorismo, “como uma espécie de fundamento mágico, coloca por terra toda e qualquer resistência da dogmática penal”. Estar-se-ia favorecendo uma legislação punitiva desviada dos mais elementares princípios dogmáticos penal de um Estado Democrático de Direito.

O terrorismo tem sido considerado um dos campos do direito penal moderno em que as garantias penais e processuais penais tem sofrido forte restrição, nos moldes do que GarciaPablos de Molina define como um movimento neocriminalizador de máxima intervenção (ALMEIDA, et. al. 2016).

Sobre uma inicial relação entre o terrorismo e o Direito penal do inimigo, surgem duras críticas aos fundamentos em relação à distinção “pessoa x inimigo” elaborada na teoria. Como elaborou Jakobs (2009, p. 64):

Na concepção do Direito penal do inimigo, como paira sobre o terrorista uma insegurança cognitiva de que vá se comportar como pessoa, não só não pode esperar ser tratado ainda como pessoa, mas o Estado não deve trata-lo, como pessoa, já que do contrário vulneraria o direito à segurança das demais pessoas.

Sob tal perspectiva, elaborada por Jakobs, o tratamento penal antiterror deveria ser o mais rigoroso possível, suprimindo garantias não só na esfera processual, mas alcançando a execução penal. A fundamentação acima, como se disse, é alvo das mais profundas críticas pela doutrina. 
Trazemos à lume as análises de Manuel Monteiro Guedes Valente, que possui obra dedicada a tal propósito, e logo na nota à $2^{\mathrm{a}}$ edição de seu livro já antecipa o cunho de seus apontamentos (2016, p. 7):

\begin{abstract}
A ideia de que o Direito Penal deve resolver os problemas sociais, econômicos e políticos é uma realidade na nossa ordem mundial. Mas é uma ideia errada e dotada de pouca ou inexistente cientificidade. O caminho de belicizar o Direito penal apenas nos traz o espectro do medo e da insegurança e nunca nos garante uma segurança real e efetiva. É uma utopia pensar que o Direito penal do inimigo nos produz um espaço e tempo de segurança. Produz exclusão, produz alienação social e política, produz um espaço e um tempo de pessoas e não pessoas, de amigos e inimigos.
\end{abstract}

O autor português explana que a satisfação de determinadas demandas de segurança absoluta relacionadas às ameaças ao terrorismo teriam destruído as fronteiras tradicionais do Estado de Direito, e atribui essa quebra principalmente entre autoridades estatais responsáveis pela persecução penal, como polícia, serviços secretos e até exércitos, no que considerou uma tentativa de legitimação de intervenções que na realidade seriam, simultaneamente, persecução penal, prevenção policial e guerra. Essa necessidade de segurança teria turvado a lógica sistemática de intervenção penal do Estado. E quanto ao terrorismo, este teria inflacionado a teoria do Direito Penal preventivo, subjugando a lógica da guerra preventiva. O agente do crime passa a ser interceptado, segundo o autor, antes de ter lesionado ou colocado em perigo de lesão um bem jurídico, porque é um Direito que tem como base a segurança dos outros (VALENTE, 2016).

Outra crítica constante às concepções de Jakobs se refere à questão da insuficiência do Direito Penal em sua prevenção geral negativa diante de terroristas suicidas.

A crítica parte do pressuposto de que não haveria capacidade mínima de dissuasão possível perante os terroristas suicidas. Como afirma Débora de Souza de Almeida:

O Direio Penal, portanto, não teria idoneidade técnica para intimidar a prática de tal crime, sendo a prevenção primária a via adequada. Embora não se possa afirmar com exatidão que uma norma denominada simbólica não contribua de forma alguma à dissuasão, pois é difícil ou impossível quantificar ou identificar quantos crimes deixaram de ser cometidos em virtude do suposto efeito preventivo-geral negativo, há de se apontar que, em se tratando de terrorismo suicida, a crítica a esta finalidade da pena angaria mais consenso (Almeida, et. al., 2017, p. 67).

Além de afirmar que a prevenção primária seria a única via adequada, sem dizer, no entanto, de que modo ou com que medidas jurídicas ou práticas tal prevenção poderia ser implementada, os autores afirmam que mesmo em países cuja lei antiterrorismo são mais 
rigorosas, com penas severas e supressão de determinadas garantias, o terrorismo não restou intimidado, e sim as ações cada vez mais tendentes a desfechos suicidas se tornaram mais constantes. Afirmam que a prevenção geral, ainda que endurecida, não seria suficiente para dissuasão (ALMEIDA, et. al., 2017).

Sobre a citação acima, e a deia de que o Direito Penal não teria idoneidade técnica nem mesmo para intimidar o terrorismo, critico: há que se refletir sobre o fato de, para todos os crimes que o direito penal não logra um chamado êxito, não seria este hábil a ser instrumento idôneo por parte do Estado para proteger bens jurídicos e direitos fundamentais, sobretudo como ultima ratio? Se no Brasil o crime de roubo não apresenta diminuição em seus índices é sinal de que deve ser abolido o tipo penal do art. 157 do Código, por exemplo? Creio que a conclusão é precipitada e carece de maior reflexão sobre todas as causas e consequências da tutela jurídico penal em detrimento do terrorismo. Afastar o direito penal seria, aí sim, medida de violência, haja vista que só a violência seria tal instrumento de enfrentamento, ou seja, uma verdadeira e literal "guerra ao terror”. Não se pode deslegitimar uma norma em razão da crescente do crime que ela visa prevenir. Obvio que a concepção dos autores acima exposta olvida de razões de cunho político, religioso, social e até ideológico que podem ter se potencializado e fomentado os ataques suicidas.

\subsection{A intrigante questão do cenário da bomba-relógio (ticking bomb scenario theory)}

A chamada "teoria do cenário da bomba-relógio" trata de uma questão que leva a fomentar ainda mais a crítica à capacidade do Direito Penal e do Estado de coibir determinadas práticas terroristas extremas, bem como nos leva à reflexão sobre o limite de atuação estatal em cenários de complicado risco. Segundo Débora de Souza de Almeida:

\footnotetext{
é uma formulação que visa, por meio da tortura de seus suspeitos de conhecer ou integrar planos de ataques terroristas, a obtenção pelo Estado de informações específicas e essenciais em prol da resolução de uma situação extrema que põe em perigo a vida de um grande número de pessoas. Trata-se, portanto, de uma técnica em caráter de emergência que objetiva prevenir e/ou combater atos terroristas iminentes, desativando o ‘cenário da bomba-relógio’ (Almeida, et. al., 2017, p. 75).
}

Para exemplificar a situação, imaginemos: um terrorista sabidamente integrante de uma organização que vem cometendo graves ataques é capturado em uma situação de ameaça por exemplo de uma bomba em local de aglomeração de civis, ou mesmo de uma bomba 
nuclear. Supondo-se uma convicção de que o terrorista capturado seja o único capaz de desarmar a bomba ou indicar uma salvação, seria legítima a tortura contra ele?

Dessa teoria decorrem algumas fundamentações que, longe de nos apontar uma concepção conclusiva, nos leva a inquietantes ponderações: poderia se fundamentar em estado de necessidade, também em legítima defesa, tanto individuais como de terceiros ou coletiva; também se sugere a possibilidade de uma autorização de cunho ex ante, ou seja, uma autorização judicial prévia para alguma prática invasiva (abusiva em situações normais), uma espécie de "mandado de tortura"; ainda, uma justificação ex post facto, isto é, uma forma de ratificação judicial de determinada ação.

Como mencionamos, um posicionamento a respeito enseja penosa perquirição, sobretudo pelo fato de, ao menos em nosso sentir, o direito a não ser torturado talvez seja o direito que mais se aproxime de um patamar absoluto, perante o qual o Estado jamais poderia se imiscuir a violar, nem mesmo por meio de suas normas ou instrumentos jurídicos válidos. Legitimar a tortura, mesmo que em situações de complexa gravidade, é medida perigosa.

\subsection{Alguns contrapontos às críticas}

Em meio ao farto arsenal de críticas às proposições funcionalistas, pouco se lê acerca de soluções para o gravíssimo problema que ela busca enfrentar. Ainda com Débora de Souza de Almeida, nota-se que:

mesmo diante de todas as dificuldades aqui apontadas, impende empregar esforços por uma resposta refreadora aos avanços terroristas. Afinal, como bem conclui Bravo Lira "el mundo no puede quedar a merced de la violência, sea de quien sea, terroristas, guerrilleros o uma superpotência. Es urgente retomar la tarea, siempre inconclusa, de hacer prevalecer el derecho sobre la violência" (Almeida, et. al., 2017, p. 66).

A maioria das críticas ao Direito Penal do inimigo estão relacionadas, necessariamente, à repreensão que grande parte da doutrina faz aos chamados novos paradigmas que o Direito Penal enfrenta na modernidade: um excesso de simbolismo com a inflação de crimes, a flexibilização de determinadas garantias e princípios até então consagrados, retomada de políticas criminais voltadas à eficiência preventiva. Muitas dessas críticas, no entanto, dizem respeito aos modelos de Direito Penal que costumam ser rotulados de linhagem de um Direito Penal do inimigo, ou de um direito autoritário. Mas o rechaço de 
plano por parte da doutrina parece se explicar somente a partir de dispositivos refratários, meramente emocionais, que tenta impregnar a ideia de que algo simplesmente não deve ser (MORAES, 2011). Em outras palavras, poucas são as críticas que ultrapassam os argumento retóricos em relação ao termo adotado por Jakobs e sua relação com o cidadão.

A própria expressão e referência ao “inimigo” suscita prejuízos motivados pela indubitável carga ideológica e emocional do termo. Ninguém quer legitimar uma guerra por parte do Estado contra alguns dos "seus".

Esclarecendo determinadas críticas, Alexandre Rocha Almeida de Moraes (2011, p. 262) observa:

É de se ressaltar, contudo, que a terminologia utilizada aparenta ter sido cuidadosamente escolhida por Jakobs com a clara intenção provocativa. Tão provocativa que, conforme mencionado, grande parte da doutrina se baseia exclusivamente na terminologia para fazer alusão ao desrespeito de princípios constitucionais e para acentuar a censura à proposta de supressão de garantias para aplicação deste modelo de política criminal.

Um exemplo de entendimento que demonstra essa consequência da escolha provocativa do termo inimigo por Jakobs, conforme Moraes explanou acima, é o de Manuel Monteiro Guedes Valente, para quem:

\begin{abstract}
A mudança de paradigma penal (material - aumento da moldura das penas, ampliação do âmbito da punibilidade dos atos preparatórios e dos atos de execução, aumento dos tipos legais de perigo abstrato) e processual (diminuição das garantias processuais penais, aumento das competências das polícias criminais sem prévio controle e autorização das autoridades judiciárias), que converte o cidadão em inimigo ou em 'coisa' pelo processo de despersonalização e que retrocede à vivificação do Direito penal de autor [...] (Valente, 2016, p. 68 e 69).
\end{abstract}

Ora, leitura atenta do trecho acima demonstra que Valente conclui que aumentar penas, punir atos preparatórios, criar tipos de perigo abstrato, etc., por si só e automaticamente seria declarar o cidadão um inimigo. Em nossa análise, o autor inverte a lógica da fundamentação de Jakobs, não devendo ser considerada essa a relação de causa e consequência em relação aos mecanismos adotados contra o terrorismo e as avançadas formas de criminalidade.

Ocorre, porém, que sobre o fato de se negar o caráter de pessoa aos taxados inimigos, a quase totalidade da doutrina critica tal construção, baseada numa série de consistentes fundamentos. Tal consideração, de rotular previamente um indivíduo de inimigo, por si só, representa um não-direito. O chamado “direito penal do cidadão” seria um pleonasmo. 
Em relação à questão da expansão do Direito Penal e de sua chamada terceira velocidade, tão criticada pela doutrina contrária ao funcionalismo, é importante a compreensão da construção de Jesús-María Silva Sánchez e de sua relação com as questões aqui pesquisadas. Em oposição às posturas doutrinárias de defesa do minimalismo em um modelo ultraliberal do Direito Penal, restringindo-o a um Direito Penal básico, a posição é denominada de expansionismo, e descrita pelo citado autor como:

\begin{abstract}
A "reinterpretação" das garantias clássicas do Direito Penal substantivo e do Direito Processual Penal. Criação de novos "bens jurídico-penais”, ampliação dos espaços de riscos jurídico-penalmente relevantes, flexibilização das regras de imputação e relativização dos princípios político-criminais de garantia, não seriam mais do que aspectos dessa tendência geral, à qual cabe referir-se como o termo "expansão" (Sánchez, 2002, p. 21).
\end{abstract}

Ele divide e classifica, ainda, em “velocidades” as distintas posturas que deve o Direito

Penal adotar, sendo a terceira a relacionada ao direito penal do inimigo:

\begin{abstract}
Uma primeira velocidade, representada pelo Direito Penal ‘da prisão', na qual haverse-iam de manter rigidamente os princípios político-criminais clássicos, as regras de imputação e os princípios processuais; e uma segunda velocidade, para os casos em que, por não tratar-se já de prisão, senão de penas de privação de direitos ou pecuniárias, aqueles princípios e regras poderiam experimentar uma flexibilização proporcional a menor intensidade da sanção. A pergunta que há que colaborar, enfim, é se é possível admitir uma 'terceira velocidade' do Direito Penal, na qual o direito penal da pena de prisão concorra com uma ampla relativização de garantias políticocriminais, regras de imputação e critérios processuais (Sánchez, 2002, p. 148).
\end{abstract}

A indagação final suscitada acima por Sánchez é a mesma que nos fazemos no tópico seguinte.

\title{
1.6 Haveria legitimidade no funcionalismo sistêmico?
}

Não fica muito nítida a ideia de que a antecipação da tutela penal, com criminalização de atos preparatórios, tipos de mera conduta e que punem o perigo abstrato sejam, por si só, a “eleição de um inimigo, e consequentemente sua punição como tal, como nos dá a entender algumas das críticas ao modelo.

Também em relação à relativização de garantias penais e processuais penais, tal comparativo acerca de um direito penal do autor não se mostra tão evidente. A dúvida que ainda paira é se a relativização baseada na necessidade de um equilíbrio de proteção de direitos fundamentais pelo Estado se justifica. E embora quando se fala em relativização ou supressão 
de garantias penais e processuais penais a questão aparenta ser um ato de arbitrariedade e barbárie, uma análise cuidadosa demonstra que podem sim ser consideradas medidas proporcionais do ponto de vista de vários princípios, como por exemplo o da individualização da pena (que exige um tratamento diferenciado para cada infrator em razão do crime por ele cometido e das circunstâncias pessoais e fáticas em relação ao fato delituoso). É dizer, por exemplo, que o tratamento ofertado a um autor de um pequeno delito deve ser mais brando que o de um criminoso habitual e violento, por exemplo.

E não se pode olvidar que medidas de relativização de garantias até então consideradas como tal já são consolidadas em diversos ordenamentos, tais como o brasileiro que limita o direito ao devido processo legal (considerado como tal em determinado momento) no âmbito dos juizados especiais; as consequências referentes ao regime inicial e à progressão de regime para os crimes hediondos; e antecipação da tutela penal em relação à crimes de drogas, armas de fogo e organizações criminosas; ainda as medidas mitigadoras de direitos fundamentais (em patamar assim considerados em determinado momento, insisto) como meios investigativos mais invasivos, tais como a interceptação telefônica, quebra de sigilo de dados, bancário e fiscal, infiltração de agentes, colaboração premiada, ação controlada, etc.

\section{A LEI ANTITERRORISMO BRASILEIRA E A LEGITIMIDADE DE SEUS MECANISMOS}

Não é oportuna para este trabalho a análise integral da lei 13.260/16, tampouco o estudo crítico da completude de seus dispositivos, mas sim de alguns de seus mecanismos criminais e processuais que são apontados como sendo vestígios ou mesmo característicos de um direito penal do inimigo.

Em leitura aos comentários à lei antiterrorismo pela doutrina brasileira observamos o apontamento de alguns mecanismos de combate ao terrorismo coincidentes com os propostos por Jakobs em sua teoria funcionalista radical. O uso de conceitos relativamente abertos nos tipos penais, a antecipação da tutela penal com a tipificação de crimes de perigo abstrato e a criminalização de atos preparatórios, a cominação de penas elevadas e a aplicação de dispositivos expressos na lei de organização criminosa e na lei de crimes hediondos seriam, em análise sistemática, típicas de um direito penal do inimigo. 


\subsection{Uso de conceitos relativamente abertos na tipificação do crime}

O art $2^{\circ}$ da lei 13.260/16 expressa o que consiste o terrorismo, sendo o cerne da lei:

Art. $2^{\circ} \mathrm{O}$ terrorismo consiste na prática por um ou mais indivíduos dos atos previstos neste artigo, por razões de xenofobia, discriminação ou preconceito de raça, cor, etnia e religião, quando cometidos com a finalidade de provocar terror social ou generalizado, expondo a perigo pessoa, patrimônio, a paz pública ou a incolumidade pública.

Como se observa da redação transcrita, em alguns pontos pode ser constatada vagueza e imprecisão, "sobretudo quanto ao elemento subjetivo especial, o que, certamente, acarretará dificuldades (ou arbitrariedades) em sua aplicação” (Almeida, et. al., 2017, p. 175). Segundo os críticos, a "finalidade de provocar terror social ou generalizado" é conceito amplo e impreciso, o que feriria, em tese, o princípio da legalidade no viés da determinação taxativa.

Ocorre que tal ideia acerca da rotulação desse crime como um tipo aberto e, por consequência automática, inconstitucional por ofensa ao princípio da taxatividade, não leva em consideração que o patamar de abertura (ou, contrário senso, de taxatividade) de um tipo penal deve ser analisado à luz da amplitude de possibilidade gramatical e semântica que o texto legal visa atingir. Conforme já mencionamos em outro trabalho, oportunidade que pesquisamos sobre o patamar de abertura dos tipos penais ambientais, a lição de Nucci esclarece a impossibilidade de um ordenamento jurídico-criminal contar somente com tipos penais estritamente fechados, contendo somente elementos descritivos e objetivos. Embora o tipo penal fechado seja uma construção segura, deve-se levar em consideração também o fato de ser insuficiente para a multiplicidade de condutas e resultados existentes. A consequência dessa incapacidade de alcance máximo a todas as condutas é a exigência de uma maior flexibilidade na redação dos tipos penais, com a utilização de elementos de certo modo valorativos, embora objetivos. Daí a denominação de tipos abertos, cuja ideia firma-se pela demanda natural de interpretação, a permitir a captação de sentidos ocultos ou subentendidos, além de possibilitar a ampliação de significados, com a adaptação de vocábulos a diversas realidades (NUCCI, 2015). Sobre nossa posição acerca dos tipos penais relativamente abertos:

Ressalte-se, no entanto, que a ideia de abertura e ampliação de significados não pode jamais se aproximar de uma imprecisão duvidosa, a ensejar possibilidades autoritárias de tipificação, mas sim de aproximação de uma realidade impossível de ser estritamente prevista em tipos penais fechados e bem definidos. A adequação do tipo penal aberto deve ser efetuada diante do caso concreto (Santos, 2016, p. 41). 
A finalidade de provocar terror social ou generalizado deve estar claramente vislumbrada para que se impute tal crime, de modo que em havendo incerteza quanto a esse elemento subjetivo especial, não se deve aplicar a norma em debate.

\subsection{Antecipação da tutela penal com os crimes de perigo}

De acordo com a alínea I do parágrafo $1^{\circ}$ do mesmo artigo $2^{\circ}$, é punível a conduta de quem "usar ou ameaçar usar explosivos, venenos[...]”. Tal previsão possui natureza de ato preparatório, e é mais um exemplo de crime formal, um tipo de perigo, cujos bens jurídicos tutelados são a incolumidade pública, o perigo comum e a paz pública.

A discussão referente à legitimidade ou constitucionalidade de crimes de perigo ainda é comum na doutrina, inclusive em razão de ser um mecanismo que caracteriza um Direito Penal prospectivo, preventivo, que antecipa a incidência da tutela penal para antes de um efetivo resultado naturalístico. Tais características, conforme já anteriormente abordado, estavam presentes na concepção funcionalista extremada de Jakobs, e também por este motivo o coro crítico se faz avolumado.

Quanto a esse uso de tipos de perigo, que dá ensejo à pecha de direito penal de risco, vale a recordação de que já na década de 1940 tipos de mesma natureza estavam em pleno vigor no Código Penal, ou seja, desde há muito a dogmática já discutia tal mecanismo, não sendo invenção desse novo direito penal do inimigo. E em relação a determinados perigos, o resultado naturalístico de diversos atos tais como os referentes ao uso de explosivos e armas letais não deve ser exigido para a incidência penal, sob pena de, aí sim, tornar o Direito Penal totalmente insuficiente para tutelar uma imensa gama de condutas reprováveis. A punição desses atos ameaçadores não deve ser a regra, mas devem sim ser levados a cabo pelo Direito Penal para determinados riscos, como é o caso do crime em questão diante de uma ameaça terrorista.

\subsection{Antecipação da tutela penal com a punição de atos preparatórios:}

Bem mais polêmica é a questão da expressa previsão da punição de atos preparatórios, ineditamente previstos no ordenamento brasileiro para os crimes de terrorismo. 
Prevê o artigo $5^{\circ}$ da lei: "Realizar atos preparatórios de terrorismo com o propósito inequívoco de consumar tal delito: Pena - a correspondente ao delito consumado, diminuída de um quarto até a metade”.

Redação como essa abre espaço para densa e interessante discussão. Em que pese a antecipação da tutela para a punição de determinados atos considerados preparatórios a outros crimes já ser consolidada na legislação brasileira, a exemplo da associação criminosa e do porte ilegal de arma de fogo, por exemplo, até então se justificava, ou se buscava justificar a existência da tutela de bens jurídicos difusos como a incolumidade pública e a paz pública, por exemplo. Ocorre que agora a expressão "realizar atos preparatórios" coloca em jogo a dogmática penal a respeito do iter criminis, bem como do reconhecimento do princípio da materialização ou exteriorização do fato, em que não há crime sem conduta, e da ofensividade ou lesividade, em que não há crime sem uma ofensa a um bem jurídico, que por sua vez tem que ser bem alheio ao agente.

Uma atenção e cuidado maiores se deve ter em relação a esse artigo em razão da possibilidade que se cria de punição da preparação da preparação, uma vez que alguns tipos penais já tipificam atos preparatórios, e conjugados com o mandamento do artigo em comento, avançam ainda mais na antecipação.

Segundo a lição de Luis Flávio Gomes, em obra coletiva já citada (Almeida, et. al., 2017, p. 243):

\begin{abstract}
A exagerada antecipação da tutela penal, com a criminalização de atos preparatórios de atos preparatórios que não revelam efetivo perigo para o bem jurídico, nos parece de inconstitucionalidade manifesta, porque implica na imposição de uma pena a um fato que não significou concreto ou real risco para o bem jurídico protegido. Por força do princípio da proporcionalidade somente se justifica a imposição de uma sanção penal quando um bem jurídico relevante correu perigo ou foi efetivamente lesado. Quando a conduta apresenta remota distância frente ao bem jurídico (ou seja: quando o bem jurídico não entra no raio de relevância da periculosidade da conduta) a incidência do direito penal viola o princípio da ofensividade bem como o da proporcionalidade. $\mathrm{O}$ direito penal não pune o agente que tem intenção de matar e que está numa esquina esperando a vítima passar por ali. Estar na esquina significa preparação. Nesse caso o bem jurídico vida ainda não entrou em perigo. Logo, essa preparação não é punível. Se o direito penal não pune quem está na frente da casa da vítima esperando-a para mata-la, porque seria usado para punir quem (ainda) está ‘fabricando' o explosivo em casa para usá-lo em um ato terrorista?.
\end{abstract}

Conclui o mesmo mestre que (p. 245): 
A antecipação da tutela penal não pode chegar, portanto, ao extremo de contemplar um modelo de crime centrado exclusivamente no desvalor de ação (esse é o caso do perigo abstrato presumido) ou reconduzíveis à ‘subjetivação’ do Direito Penal (como é o caso da teoria subjetiva da tentativa, que se contenta apenas com a intenção do agente) (Almeida, et. al., 2017, p. 245).

O mecanismo da antecipação da tutela penal necessita evoluir a ponto de sanar qualquer chance de irregularidade como essa observada pelas acepções acima, sob pena de deslegitimar toda a sistemática do ordenamento em pauta, e em consequência, alargar ainda mais a insuficiência de proteção aos bens jurídicos aos quais a tutela é dirigida.

\subsection{O elevado patamar de pena}

A pena prevista ao crime de terrorismo é de doze a trinta anos, e é considerada por muitos muito elevada, já que a pena privativa de liberdade não deveria ser superior a dez anos (na visão por exemplo de Ferrajoli).

A respeito de aumento de pena e de penas elevadas a questão também ganha vários contornos. Em razão da falência do nosso sistema de ressocialização, é forte a corrente que defende que “cadeia não ressocializa”, o que enfraquece a legitimação de penas severas, e rechaça qualquer rigorismo em relação ao quantitativo das penas.

Costumamos no entanto indagar: Mesmo diante da chamada falência das penas e do sistema prisional, é aceitável um cidadão cometer, por exemplo, um crime violento como um roubo à mão armada e ser condenado ao cumprimento de pena em regime semiaberto? Deve a sociedade compreender como natural o fato de ter que conviver diante da constante ameaça de voltar a se deparar com a cena e o autor do crime em que foi vítima?

Cremos que a dosagem da pena deve ser proporcional e respeitar patamares condizentes com a possibilidade de ressocialização e com a dignidade humana, e em condições realmente dignas e aceitáveis de submissão por parte daqueles que se desviaram dos padrões mínimos de convivência social. No entanto a efetividade do Direito Penal não deve ser simplesmente suprimida com base em concepções fantasiosas e descompromissadas com seu desiderato. Conforme justifica Gabbelini:

A nova roupagem da missão penal deve manter os padrões do direito penal clássico, rico em conceitos e dogmas para proteção do sistema penal acrescentando uma nova via para contundir a nova criminalidade, em especial, o terrorismo, que atinge não só a pessoa humana como também todo o sistema, causando pânico, caos e desordem social (Gabbelini, 2016, p. 160). 


\subsection{Aplicação das disposições da lei de organização criminosa: meios “invasivos” de investigação}

A previsão de aplicação das disposições da lei de organização criminosas aos crimes de terrorismo também enseja comparação com o Direito Penal do inimigo. Técnicas investigativas e processuais como a infiltração de agentes, colaboração premiada, interceptação telefônica, quebra de sigilo bancário e fiscal, captação ambiental, ação controlada, entre outras são objeto de severas críticas baseadas na dogmática penal clássica.

Nesse ponto revive-se a análise dos institutos investigativos previstos em algumas legislações, de cunho mais invasivo em comparação aos meios clássicos de investigação. Cada um desses novos meios merecem ser amplamente estudados, sob o aspecto de sua legitimidade, forma de utilização e banalização, entre outras diversas questões. O que se chama atenção, no momento, é sua necessidade diante do reconhecimento de que a criminalidade altamente organizada e eficiente requer uma prevenção e persecução aprimorada.

A necessidade de evolução do aparato jurídico estatal é evidente, e inclusive atrasada em relação à evolução dos meios criminosos habitualmente praticados na atualidade.

\subsection{Aplicação das disposições da lei de crimes hediondos}

Por derradeiro a lei antiterrorismo determina a aplicação das disposições da lei de crimes hediondos ao crime de terrorismo. Sendo este um crime considerado equiparado aos crimes hediondos, de acordo com uma interpretação do dispositivo constitucional que manda criminalizar algumas condutas consideradas dignas de tutela penal pelo constituinte, não podia deixar de fazer incidir seus mecanismos. São eles a insuscetibilidade de fiança, graça, anistia e indulto; o cumprimento da pena em regime inicial fechado, e maior rigor para progressão de regime.

Do próprio mandamento constitucional de criminalização e do pressuposto lógico de proporcionalidade em sentido estrito que se justifica o tratamento mais rigoroso aos crimes hediondos e equiparados, não havendo que se falar em ilegitimidade de aplicação de tais mecanismos simplesmente por se assemelharem a algumas disposições elaboradas por Jakobs em sua concepção de Direito Penal do inimigo, desacompanhadas do verdadeiro fundamento de proporcionalidade que os justifica. 


\section{CONCLUSÃO}

É certo que a própria constituição trouxe um mandado expresso de criminalização de alguns crimes considerados graves, demonstrando que é objetivo da república a tutela penal dos bens jurídicos envolvidos, inclusive de maneira mais rigorosa que os demais. É o que se pode compreender do texto da Carta Magna quando expressa como princípio da república nas relações internacionais o repúdio ao terrorismo (art. 4 VIII), e quando determina que serão considerados crimes inafiançáveis e insuscetíveis de graça ou anistia o terrorismo, o tráfico e a tortura.

Em respeito à proporcionalidade em ambas as suas vertentes, não há como pleitear-se um tratamento exatamente idêntico aos crimes de pequena monta ou de menor potencial ofensivo em comparação aos crimes mais horrorosos, e essa interpretação é inseparável do tratamento processual, ou seja, se o processo por si só representa um constrangimento para qualquer acusado, por óbvio que o constrangimento deve ser menor quando se trata de crimes de menor potencial ofensivo.

No decorrer deste trabalho pudemos compreender os reais fundamentos da teoria funcionalista sistêmica de Günter Jakobs, bem como as principais críticas que a acompanham, para em seguida constatar que diversos mecanismos característicos do modelo apresentado encontra-se vigorando em diversos ordenamentos. E especificamente em relação ao terrorismo, notamos que vários deles se mostram legítimos e necessários ao objetivo que se destina o Direito Penal frente ao terrorismo, que enseja uma efetividade e uma proteção eficiente.

Um equilíbrio de proteção exige mecanismos mais efetivos diante de condutas complexas, e a dogmática penal deve se empenhar em destrinchar as novas formas de criminalidade buscando esse equilíbrio entre eficiência e garantismo, de modo que nenhuma invasão no âmbito de direitos fundamentais individuais seja permitida a ponto de configurar abuso ou arbitrariedade por parte do Estado, ao mesmo tempo em que a coletividade e o direito não padeçam diante da violência, do medo e da criminalidade.

\section{REFERÊNCIAS BIBLIOGRÁFICAS}

ALMEIDA, Débora de Souza; ARAÚJO, Fábio Roque; CUNHA, Rogério Sanches; GOMES, Luiz Flávio PINTO, Ronaldo Batista. Terrorismo: Comentários artigo por artigo, à lei 13.260/2016 e aspectos criminológicos e político-criminais. Salvador: Juspodivm, 2017. 
BAUMAN, Zygmunt. Medo líquido. Tradução: Carlos Alberto Medeiros. Rio de Janeiro: Jorge Zahar, 2008.

. Danos colaterais: desigualdades sociais numa era global. Tradução: Carlos Alberto Medeiros. Rio de Janeiro: Jorge Zahar, 2013.

BOBBIO, Norberto. O futuro da democracia: uma defesa das regras do jogo. Tradução Marco Aurélio Nogueira. 6. ed. Rio de Janeiro: Paz e Terra, 1986.

BRIGAGÃO, Paula Naves. O funcionalismo no direito penal brasileiro. (epub). Editora Freitas Bastos, 2010.

CALLEGARI, André Luís; LYNETT, Eduardo Montealegre; JAKOBS, Günter; MELIÁ, Manuel Cancio. Direito Penal e funcionalismo. Porto Alegre: Livraria do Advogado, 2005.

D’ÁVILA, Fábio Roberto. Liberdade e segurança em direito penal. O problema da expansão em direito penal. Revista Eletrônica de Direito Penal - AIDP-GP, ano 1, v. 1, jun. 2013, pp. $65 / 73$.

DEGAUT, Marcos. O desafio global do terrorismo: política e segurança internacional em tempos de instabilidade. Edição do autor: Brasília, 2014.

FERRAJOLI, Luigi. Direito e razão: teoria do garantismo penal. Tradutores: SICA, Ana Paula; CHOUKR, Fauzi Hassan, et al. $3^{\mathrm{a}}$ ed. rev. São Paulo: Editora Revista dos Tribunais, 2002.

FERRAZ JR., Tércio Sampaio. Introdução ao estudo do direito: técnica, decisão, dominação. 5. ed. rev. e ampl. São Paulo: Editora Atlas, 2007.

GABBELINI, Rogério Batista. O delito de terrorismo no ordenamento penal: Lei $\mathrm{n}^{\circ}$ 13.260/2016. Editora Millennium: Campinas, 2016.

JAKOBS, Günter; MELIÁ, Manuel Cancio. Direito penal do inimigo: noções e críticas. Porto Alegre: Livraria do Advogado, 2009.

JAKOBS, Günther. Direito Penal do Inimigo. Organização e Introdução: Luiz Moreira e Eugênio Pacelli de Oliveira. Tradução: Gercélia Batista de Oliveira Mendes. Rio de Janeiro: Lumen Juris, 2008.

MOCCIA, Sérgio. Emergência e defesa dos direitos fundamentais. Revista Brasileira de Ciências Criminais, ano 7, n. 25, jan-mar, 1999, p. 58/91.

MORAES, Alexandre Rocha Almeida de. Direito Penal do Inimigo: a terceira velocidade do Direito Penal. Curitiba: Juruá, 2011. 
NUCCI, Guilherme de Souza. Princípios constitucionais penais e processuais penais. 4. ed. rev., atual. e ampl. Rio de Janeiro: Forense, 2015.

SÁNCHEZ, Jesús-María Silva. A Expansão do Direito Penal: aspectos da política criminal nas sociedades pós-industriais. Tradução: Luiz Otavio de Oliveira Rocha. São Paulo: Revista dos Tribunais, 2002.

SANTOS, Jordan Espíndola dos. Os tipos penais ambientais abertos e o princípio da determinação taxativa: considerações sob a perspectiva do garantismo penal integral. In $X X V$ Congresso do CONPEDI - Curitiba. Direito Ambiental e Socioambientalismo IV. Coordenadores: Ana Paula Basso, Hertha Urquiza Baracho. Florianópolis: CONPEDI, 2016.

VALENTE, Manuel Monteiro Guedes. Direito Penal do inimigo e o terrorismo: o progresso ao retrocesso. Coimbra: Almedina, 2010. 